\title{
Multiple Welding of Long Fiber Epoxy Vitrimer Composites
}

Manuscript accepted in Soft Matter

DOI:10.1039/C6SM00257A

\author{
Erwan Chabert $^{a}$, Jérôme Vial ${ }^{b}$, Jean-Pierre Cauchois ${ }^{c}$, Marius Mihaluta ${ }^{c}$ and François Tournilhac ${ }^{a} *$
}

Vitrimers appear as a new class of polymers as they can exhibit mechanical strength and are insoluble even at high temperatures like thermosets and yet, like thermoplastics, they are heat processable, recyclable and weldable. The question arises whether this welding property is maintained in composite materials made of more than $50 \mathrm{vol} \%$ of reinforcing fibers. In this paper, we analyze quantitatively the bond strength of epoxy vitrimer based composite plates made by resin transfer molding and compare them to their non-vitrimer counterparts made of a standard thermoset epoxy. It is demonstrated that only epoxy vitrimer samples show substantial bond strength and the ability to be repeatedly welded thanks to the exchange reactions which promote improved surface conformity and chemical bonding between the adherands at the joint interface. This opens the way towards joining composite parts without adhesives nor mechanical fasteners.

\section{Introduction}

Vitrimers are crosslinked organic networks yet able to flow thanks to a unique feature: a chemical structure that allows network's links to exchange under thermal stimulation, while keeping the number of links constant. Vitrimers have first been illustrated by the group of Leibler through the design of polyhydroxy ester networks in which connecting ester bonds can exchange by transesterification. ${ }^{1}$ Such networks are insoluble like thermosets but when heated and in the presence of well chosen catalysts, ${ }^{2}$ exchanges are fast and the material can flow by reorganization of the network's topology. They thus proved to be heat-processable, recyclable and weldable like thermoplastics. $^{3}$

Vitrimers are distinguishable from thermosets, from thermoplastics and from systems with reversible bonds ${ }^{4-11}$ in which the network disjoins at high temperature. They indeed form a new class of polymer materials. In aforementioned vitrimer prototypes, ${ }^{1}$ the polyhydroxyester network was synthesized by epoxy chemistry. Since then, a number of different chemical systems were recognized to form vitrimers, based on transesterification ${ }^{12-15}$ as well as other suitable exchange reactions. ${ }^{16-20}$ A review of the current developments of vitrimers has also been published ${ }^{21}$ and besides, covalent adaptable networks that are based on light-induced radical exchange reactions ${ }^{22-25}$ as well as thermal scissionrecombination processes involving short-lived radicals ${ }^{26-27}$ share, to some extent, the characteristic features of vitrimers.

\footnotetext{
a. ESPCI-ParisTech, PSL Research University, Matière Molle et Chimie, UMR 7167 CNRS-ESPCI, 10 rue Vauquelin, 75005, Paris, France. francois.tournilhac@espci.fr b. ESPCI-ParisTech, PSL Research University, Sciences analytiques, bioanalytiques et miniaturisation, UMR CBI 8231 CNRS/ESPCI/UPMC

c. Institut de Soudure, Rond-Point Patton, B.P. 5020, F-57506 Saint-Avold Cedex

+ Footnotes relating to the title and/or authors should appear here.

Electronic Supplementary Information (ESI) available: [details of any supplementary information available should be included here]. See DOI: $10.1039 / x 0 x x 00000 x$
}

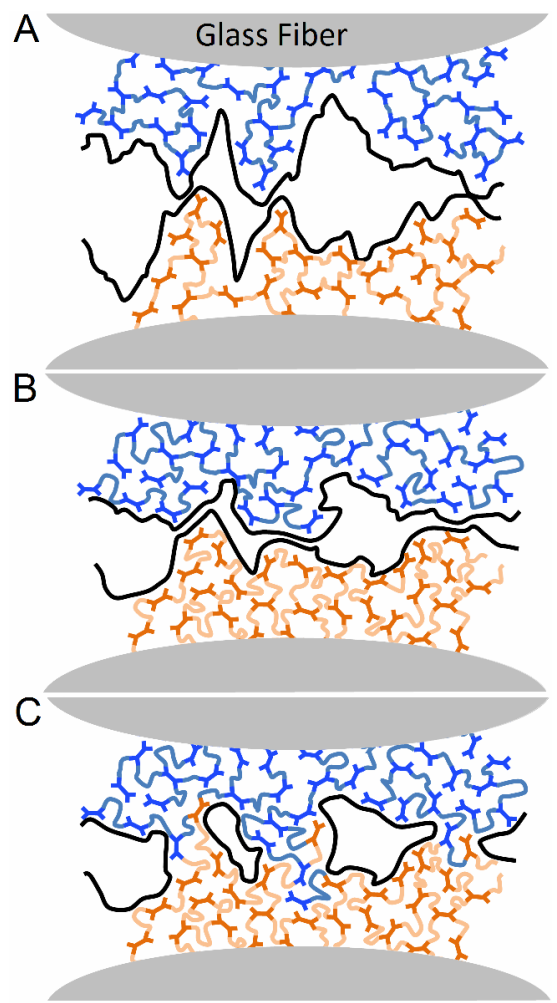

Figure1. Schematic view showing the mechanisms expected to promote significant adhesion when two epoxy vitrimer composites plates are put in contact under a load $P$ at high temperature $T$. $\mathbf{A} \rightarrow \mathbf{B}$ Exchange reactions within the vitrimer network enable the matrix to flow thus increasing surface conformity and fostering the contact between top and bottom adherands; $\mathbf{B} \rightarrow \mathbf{C}$ Upon contact, exchange reactions between top and bottom adherands occur, creating bonds at the interface.

Yet, epoxy-based materials are present in a number of applications where the properties of vitrimers could be an asset. In particular in composites, epoxy resins combined with glass fibers or carbon fibers are widely used, mostly in structural applications ranging from civil infrastructure to high performances vehicles because they achieve both substantial 
weight reduction compared to metals and high mechanical performances. ${ }^{28}$ Another advantageous feature of epoxies in composites' implementation is that, before curing, the reactive mixture is very fluid (typically less than 1Pa.s) making it compatible with the resin transfer molding (RTM) technique. ${ }^{29}$ Ideally a composite structure would be designed and made in one part but size and risks of defects are limiting factors and often force engineers to design it in more than one part. Thus there will inevitably be joints to combine the parts together. In contrast to thermoplastic composites that can be assembled by a variety of welding techniques, ${ }^{30-32}$ thermoset composites exhibit better mechanical properties and insolubility but they are not weldable because reprocessing is impossible after cure's completion due to the permanent crosslinks. Joints of thermoset composites are either mechanically fastened ${ }^{33-34}$ or adhesively bonded. ${ }^{35-40}$ Adhesives are often preferred because conventional mechanical joints increase the structure's weight and usually entail cutting fibers which reduces the structural integrity because of the stress concentration that it creates. ${ }^{41}$ Other methods of assembly have been considered: the presence of remaining reactive functions (e.g. epoxy) after cure was shown to increase heat-promoted adhesion between two freshly cracked planes; ${ }^{42}$ dissolving a thermoplastic as a healing agent inside a thermoset has also been investigated but leads to a loss of mechanical properties of the virgin material. ${ }^{43-44}$

The unusual combination of properties of vitrimers is very appealing both fundamentally and practically, in particular for composite materials. As opposed to the infinite viscosity of thermosets and their definitive shape after curing, vitrimers exhibit a high but finite $\left(<10^{12} \mathrm{~Pa} . \mathrm{s}\right)$ viscosity which permits to envision new shaping, reparation and postcure techniques. The purpose of this paper is to investigate one of these perspectives. Carbon nanotube (CNT)-vitrimer composites have been described ${ }^{14}$ where the photothermal effect of CNT was exploited to stimulate the welding through exchange reactions. We propose to extend the concept of autogenous welding of vitrimers already mentioned in previous works ${ }^{3,14}$ to fiber-reinforced vitrimer composites. A first motivation of this study was to prepare large size $\left(0.5 \times 0.5 \mathrm{~m}^{2}\right)$ defect-free composite plates in a thickness range representative of major automotive and aerospace applications. We targeted RTM for its unique ability to produce high quality structural parts in optimum safety conditions. We prepared a continuous glass fiber reinforced composite plate using the epoxy vitrimer as matrix and another for comparison purposes using a standard epoxy as matrix. Our second motivation was to explore quantitatively the process of autogenous welding by assembling fully cured composite samples under pressure and temperature without the use of any adhesive or mechanical fasteners. The joint force at break is measured. We analyze the contribution of the underlying physical and chemical mechanisms by a comparison with the non vitrimer epoxy control.

Adhesion between a polymer and a random rough surface was studied by Creton and Leibler. ${ }^{45}$ For contact times shorter than the terminal relaxation of the polymer, bonding is determined by the contact area eventually obtained by pressing the surfaces together. This area, which may be evaluated by the classical formula of Greenwood and Williamson ${ }^{46}$ is proportional to the applied load and inversely proportional to the plateau modulus of the polymer. Thermosets in the rubbery regime (above $\mathrm{Tg}$ ) fall into this description because they have an infinite terminal time. As illustrated in Figure 1, we anticipate the situation to be dramatically different for vitrimers which are able to flow thanks to exchange reactions and thus able to conform to the rough surface with which they are in contact $(A \rightarrow B$ in Figure 1). Additionally vitrimers have the ability to constantly form new chemical bonds across the interface by exchange reactions $(B \rightarrow C$ in Figure 1$)$ whereas in standard thermosets chemical bonding could only occur if remaining reactive functions are present as a result of incomplete curing. We expect the bonding of epoxy vitrimer composites to be strongly influenced by these two factors, compared to their non vitrimer counterparts. Plus, we expect that multiple welding is possible solely for vitrimers.

\section{Experimental}

\section{Sample preparations}

Materials The study was carried out using 600T plain-weave glass fabrics (Surface density: $600 \mathrm{~g} / \mathrm{m}^{2}$ ) supplied by Chomarat. A light poly(ethylene terephtalate) (PET) cloth $\left(30 \mathrm{~g} / \mathrm{m}^{2}\right)$ was layered on top of the glass fiber plies. Liquid resins components were provided by Huntsman and preheated to $50^{\circ} \mathrm{C}$ before mixing. According to the products informations, Araldite LY564 is a mixture of Bisphenol-A epichlorhydrine epoxy prepolymer $(\mathrm{Mn} \leq 700 \mathrm{~g} / \mathrm{mol}$ ) and butanediol diglycidyle ether as reactive diluent, Aradur $917 \mathrm{CH}$ is a mixture of $1,2,3,6$ tetrahydro-4-methylphthalic anhydride, 1,2,3,6-tetrahydro-3methylphthalic anhydride, 1,2,3,6-tetrahydrophthalic anhydride, hexahydro-4-methylphthalic anhydride. Accelerator 960-1 is composed of 2,4,6 tris-dimethylaminomethyl phenol. Zinc acetylacetonate $\left(\mathrm{Zn}(\mathrm{Acac})_{2} \cdot \mathrm{xH}_{2} \mathrm{O}\right)$ supplied by SigmaAldrich was grinded before use.

Composite processing The glass fibers reinforced composite plates were prepared at the composites technology platform of Institut de Soudure (Saint Avold, France) by Resin Transfer Molding (RTM). The quantities of reactants are listed in Table S1. When present, zinc acetylacetonate is first mixed with the hardener, Aradur $917 \mathrm{CH}$. The epoxy component Araldite LY564 is then added. Finally the accelerator is added while stirring. The thus prepared reactive mixture is heated to $50^{\circ} \mathrm{C}$ and vacuum-injected in a preheated mold at $50^{\circ} \mathrm{C}$ which contains the layered glass fiber plies and the cloth on top. The resin is then cured at $120^{\circ} \mathrm{C}$ during $4 \mathrm{~h}$. A postcuring step is done at $160^{\circ} \mathrm{C}$ during three hours.

Autogenous welding $50 \mathrm{~mm}$ long rectangular parts were cut with a diamond circular saw out of the $3 \mathrm{~mm}$ thick composite 
plates. The joint surface is set at a $15 \mathrm{~mm}$ width and a $20 \mathrm{~mm}$ length. Before the first adhesion, the joint surface was lightly polished with a P800 Norton sandpaper under water in order to remove the traces of contaminants present on the adherand surfaces (e.g. the unmolding agent used during the RTM process). It was then wiped with a clean tissue. Each sample was individually and carefully prepared so that the two adherands were well aligned during adhesion. Welding was performed at $160^{\circ} \mathrm{C}$ during $1 \mathrm{~h} 30$ under a load of $500 \mathrm{~N}$ or $1320 \mathrm{~N}$ applied thanks to a home built setup (ESI, Figure S1). All samples have been polished in the same manner and present a Gaussian distribution of all asperities heights (ESI, Figure S2).

\section{Instrumentation}

Mechanical testing Tensile and lapshear tests were run on an Instron Universal Testing Machine (model 5564). Tensile properties were measured according to ISO $527-1 .^{47}$ For lapshear tests, two compensation shims of appropriate thickness ( $2 \%$ error maximum) made out of the same material as the adherands' were stuck at the edges using a cyanoacrylate glue, so that the adhered section and the two edges have the same thickness. With this care, the line of force is guaranteed to be aligned with the welded section. To get the best alignment of the grip axis with the joint section and to prevent the joint from breaking from induced moments, the upper grip was left free to rotate around its horizontal attachment pin. Then, the pneumatic grips were slowly closed until a 7 bar pressure is reached. The lapshear joint measurements were performed at a cross-head speed of 0.5 $\mathrm{mm} \cdot \mathrm{min}^{-1}$ at room temperature.

Rheology Measurements of storage, G' and loss, G" moduli during the curing reaction have been performed at $1 \mathrm{Rad} / \mathrm{s}$ and $0.5 \%$ applied strain using an Anton-Paar MCR 501 rheometer. A $15 \mathrm{~mm}$ diameter parallel planes geometry was used to ensure that the measured torque remains well below $230 \mathrm{mNm}$ throughout the curing process. In all cases, it was checked that the actual deformation is equal to the targeted one. Viscosity measurements of uncured resins (reported in $\mathrm{SI}$ ) were carried out on the same rheometer in the $25 \mathrm{~mm}$ parallel plane geometry. Stress relaxation experiments of fiber-free cured specimens were conducted at $160^{\circ} \mathrm{C}$ with $0.5 \%$ applied strain in the torsion mode using an ARES G2 rheometer equipped with a rectangular torsion fixture (torsion bars: 42 $\mathrm{mm}$ long $15 \mathrm{~mm} \times 1.7 \mathrm{~mm}$ thick).

Optical microscopy was carried out in reflection and in transmission using a LEICA DMR DAS microscope equipped with a 5x/0.12 PL Fluotar Objective.

Differential Scanning Calorimetry (DSC) DSC was performed on a TA Q1000 apparatus. Two heating and one cooling cycles were recorded from 0 to $230^{\circ} \mathrm{C}$ at $10^{\circ} \mathrm{C} / \mathrm{min}$.

Thermogravimetric Analysis Isothermal TGA measurements were run at $160^{\circ} \mathrm{C}$ and $210^{\circ} \mathrm{C}$ under a $80 \% \mathrm{~N}_{2} / 20 \% \mathrm{O}_{2}$ atmosphere using a Netzsch TG209 F1 thermal analyser.

\section{Results \& Discussion}

In epoxy vitrimers previously mentioned, ${ }^{1}$ the chemical groups able to participate in exchange reactions are ester groups and hydroxyl groups. They are generated by curing an epoxy reagent with an acid or anhydride hardener using a stoichiometry of one acyl group per epoxy group in the presence of a hydrated zinc salt catalyst. In this paper, the epoxy vitrimer matrix preparation differs from previously reported works. ${ }^{1-3}$ The basis of our reactive mixture is an epoxy-anhydride formulation based on commercial composite matrix components. ${ }^{48}$ The epoxy (Araldite LY564) and the anhydride (Aradur $917 \mathrm{CH}$ ) reagents are liquid at room temperature as opposed to the previously reported procedures based on a crystallizable model epoxy resin, diglycidyl ether of bisphenol A (DGEBA) and a solid hardener, glutaric anhydride.

The curing of epoxides by anhydride hardeners has been studied for long time. In stoichiometric conditions the main reaction is an alternate ring opening copolymerization of epoxide and anhydride giving rise to ester links. When an excess of epoxide is used, in aprotic conditions, curing takes an increasing character of epoxide homopolymerization with formation of ether links. ${ }^{49}$ Hydroxyl groups, when present in the starting resin components, react with anhydrides to produce ester and carboxylic acid functions that in turn react with epoxides to regenerate hydroxides. ${ }^{50}$ Eventually excess carboxylic acids and hydroxides can reform esters. ${ }^{51}$

In the present case, esters and hydroxides are both desirable to promote exchanges by transesterification. ${ }^{3}$ The biphenol-A epichlorhydrine copolymer component of LY564 already contains hydroxide groups. Water molecules present as impurities in the reactants as well as the enol form of acetylacetone brought by the catalyst also promote formation of hydroxides. When the number of acyl groups is less than twice the number of epoxide functions, hydroxide functions in excess can survive until the end of curing.

What makes our system vitrimer is: 1) a "2:1" stoichiometry i.e. two epoxy functions for one anhydride function which indeed corresponds to one acyl group per epoxy group and 2) the use of zinc acetylacetonate $\left(\mathrm{Zn}(\mathrm{Acac})_{2}\right)$ as a transesterfication catalyst. Among catalysts previously tested in epoxy vitrimers, ${ }^{1-3}$ zinc acetyl acetonate was selected for its solubility in the resin components and stability. Yet this salt undergoes thermal degradation ${ }^{52}$ but catalytic activity is retained in the decomposition products (essentially zinc acetate). An organic catalyst like TBD is another suitable option but shows inferior thermal resilience. The epoxy vitrimer system is then called $2: 1-\mathrm{Zn}$. Our study also includes a control non-vitrimer system which follows the guidelines of the LY564/917CH user's guide ${ }^{48}$ and is called $2: 2$ because its monomer feed ratio is 1 epoxy for 1 anhydride function and does not include the zinc catalyst. The formulations of both plates are detailed in Electronic Supplementary Information (ESI) Table S1. In all cases, a liquid tri-amine (Accelerator 9601) was added, as recommended by the LY564 user's guide. Figure 2 schematically shows the preparation by RTM of 
composite plates from glass fiber plies and an epoxy vitrimer network with possible exchange reactions and from a control network without catalyst in which no exchange reactions are expected.

Before cure, our 2:1-Zn vitrimer resin formulation exhibits a viscosity of less than 0.5 Pa.s at $50^{\circ} \mathrm{C}$ like the control $2: 2$ reference formulation as featured in ESI Table S1.

a)
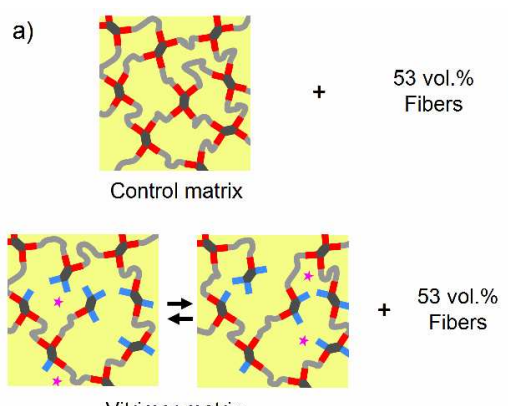

Vitrimer matrix

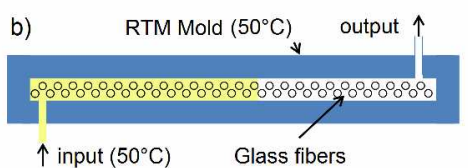

Figure 2. a) Use of the epoxy 2:1-Zn vitrimer and $2: 2$ control networks as matrices in fiber reinforced composites. Exchanges are expected solely in the epoxy vitrimer matrix due to the presence of hydroxy and ester groups (shown in blue and red respectively) and zinc catalyst (purple star); b) Schematic view of the resin transfer molding (RTM) technique for composite manufacturing; c) Weight fraction of zinc at the input and output of the RTM mold as titrated by TGA (from $30^{\circ} \mathrm{C}$ to $900^{\circ} \mathrm{C}$ at $10^{\circ} \mathrm{C} / \mathrm{min}$ ) and by elemental analysis.

A special care was brought to the good distribution of the solid catalyst (when present) throughout the composite plate. Preliminary experiments by transmission optical microscopy revealed that $\approx 1 \mu \mathrm{m}$ size crystals are still present in the reactive mixture at $50^{\circ} \mathrm{C}$ but readily dissolve above, well before crosslinking reaction take place. At $80^{\circ} \mathrm{C}$ for instance, dissolution takes about 1 minute whereas gel time is about 3040 minutes. ${ }^{48}$ The table included in Figure 2 presents the results of zinc titrations at the input and the output of the RTM mold. Both values were found identical despite the presence of the tight network formed by the six reinforcing glass fiber plies that could have filtered the zinc acetylacetonate powder in case of incomplete dissolution.

The hereby designed epoxy vitrimer system is therefore also adapted to injection molding techniques such as the Resin Transfer Molding (RTM) technique schematized in Figure 2, because efficient mixing and easy injection into the RTM mold through the closely packed reinforcing fiber plies are then possible. RTM has been selected in order to obtain large size defect-free composite plates with a high filler content (53 vol\%) with comparable surface aspects between plates and precise control of their thickness to $3 \mathrm{~mm}$. A cure cycle of $4 \mathrm{~h}$ at $120^{\circ} \mathrm{C}$ was selected. At $50^{\circ} \mathrm{C}$, viscosity remains lower than 1 Pa.s for more than 15 minutes which gives suitable conditions to inject the resin into the RTM mold (injection takes about 3 minutes). Crosslinking at $120^{\circ} \mathrm{C}$ is then evidenced by the steep increase of G' and G" curves that eventually intersect, which happends after about 20 min (Figure 3a).

DSC measurements that are presented in ESI Table S2 for each sample after cure (i.e. $4 \mathrm{~h}$ at $120^{\circ} \mathrm{C}$ ) and after 3,6 or 12 hours of postcuring under vacuum at $160^{\circ} \mathrm{C}$ led to the conclusion that a three hours postcuring step at $160^{\circ} \mathrm{C}$ is needed to ensure the final $T_{g}$ is reached. It was then applied to both 2:1Zn and 2:2 composite plates.
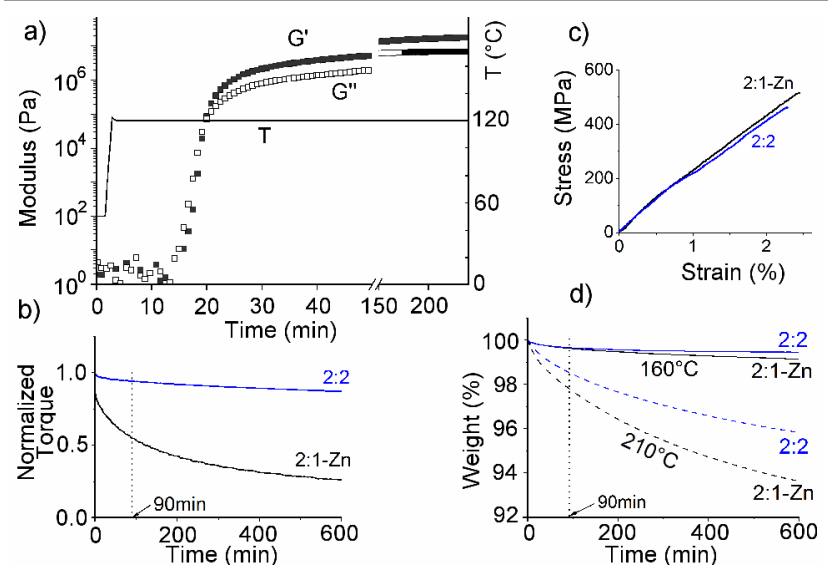

Figure 3. a) Temperature profile of the cure cycle $\left(120^{\circ} \mathrm{C}\right.$ for $\left.4 \mathrm{~h}\right)$ and time dependance of the storage $\mathrm{G}^{\prime}$ and loss $\mathrm{G}$ " moduli for the 2:1-Zn epoxy vitrimer matrix during curing. The G' G" cross-over happens after about 20 min.; b) Normalized stress relaxation (measured at $0.5 \%$ strain in the torsion mode) at $160^{\circ} \mathrm{C}$ of reference $2: 2$ and epoxy vitrimer 2:1-Zn neat matrices; c) Stress strain curves of both studied 53 vol.\% glass fiber composite plates (3mm thickness) by tensile test according to $150527-1(1 \mathrm{~mm} / \mathrm{min}$ ) at room temperature; d) Thermogravimetric Analysis (TGA) under $80 \% \mathrm{~N}_{2}$ and $20 \% \mathrm{O}_{2}$ for an isothermal treatment at $160^{\circ} \mathrm{C}$ and $210^{\circ} \mathrm{C}$ on control $2: 2$ and vitrimer $2: 1-\mathrm{Zn}$ matrices.

After cure, DMA experiments showed an elastomeric plateau regime above $\mathrm{Tg}$ (ESI Figure S4) and a swelling test in trichlorobenzene (TCB) revealed that the material swelled but did not dissolve after $12 \mathrm{~h}$ at $180^{\circ} \mathrm{C}$ (see ESI). This shows that the system is chemically crosslinked beyond the gel point. Stress relaxation experiments of fiber-free specimens are shown in Figure $3 \mathrm{~b}$ and in ESI Figure $\mathrm{S} 5$ at $160^{\circ} \mathrm{C}$ and $210^{\circ} \mathrm{C}$ respectively. At $160^{\circ} \mathrm{C}$, after $90 \mathrm{~min}$, the $2: 1-\mathrm{Zn}$ matrix relaxes $41 \%$ of stress whereas the control matrix does not. At $210^{\circ} \mathrm{C}$, the $2: 1-\mathrm{Zn}$ matrix fully relaxes the stress with a relaxation time $\tau=11 \mathrm{~min}$ while the control matrix does not. These results confirm the vitrimer nature of the $2: 1-\mathrm{Zn}$ material.

The stress-strain plot of each prepared plate is shown in Figure 3c. Both essentially show similar tensile properties thanks to their identical fiber volume fraction (53 vol.\%). The measured Young modulus is $24 \mathrm{GPa}$; the stress at break is $522 \mathrm{MPa}$ and the deformation at break is $2.5 \%$.

Thermogravimetric analysis (TGA) results are presented in Figure $3 \mathrm{~d}$. After $1 \mathrm{~h} 30$, the weight loss at $160^{\circ} \mathrm{C}$ is less than $1 \%$ for every material but significantly increases at $210^{\circ} \mathrm{C}$. Thus a higher temperature than $160^{\circ} \mathrm{C}$ might deteriorate the matrix or favor more than just exchange reactions and mask the benefits in stress relaxation (Figure $3 b$ ) of the vitrimer chemistry in comparison to the other. Welding temperature for this study has then been chosen to be $160^{\circ} \mathrm{C}$ at which both materials exhibit great thermostability. 
Another concern is the persistence of shape of the object when the pressure is applied to welding. In the linear regime, the unrecoverable deformation $\gamma$ after a time $t$ under a stress $\sigma$ scales as: $\gamma \approx \sigma t / G_{0} \tau$. Above $\mathrm{Tg}$, the neat matrix $2: 1-\mathrm{Zn}$ has a shear modulus $G_{0} \approx 10^{7} \mathrm{~Pa}$ and a relaxation time $\tau \approx 12000 \mathrm{~s}$, the predicted deformation after an applied stress of $4.4 \mathrm{Mpa}$ (the maximum applied here) for $1 \mathrm{~h} 30$ may be as large as $20 \%$ which may represent a significant change of the surface roughness but in the bulk of the composite, the actual value of $G_{O}$ is two orders of magnitude larger (measurement by three points bending at $200^{\circ} \mathrm{C}$ gave a Young modulus of $3.8 \mathrm{GPa}$ ) due to the presence of fibers and thus, predicted deformations are less than $0.2 \%$ in the compressed region.

The choice of $160^{\circ} \mathrm{C}$ was therefore found judicious to analyze the contribution of the underlying physical and chemical mechanisms especially the surface roughness. The authors are fully aware that the chosen conditions are very restrictive and better adhesion could have been achieved but they were chosen to permit quantitative comparison and the study of the importance of the contact area between adherands through multiple welding. In fact, a higher temperature has yielded to a cohesive failure of the joint as featured in ESI Figure S6 for an epoxy vitrimer composite welded at $180^{\circ} \mathrm{C}$.

Bond strength was determined through a lapshear test ${ }^{39,53}$ in a geometry inspired by $1504587 . .^{54}$ Welding was performed at $160^{\circ} \mathrm{C}$ during $1 \mathrm{~h} 30$ under a load of either 500 or $1320 \mathrm{~N}$. The joint surface was set at $15 \times 20 \mathrm{~mm}^{2}$. The procedure is described in the experimental section and the shape of specimens is depicted in Figure 4.

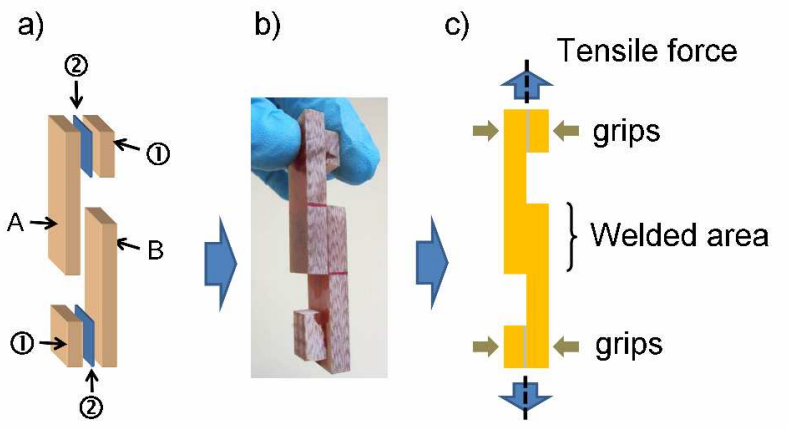

Figure 4. a) Exploded view of lapshear specimens (1) shims, (2) glue, A, B: composite adherands; welding is performed at the central part. b) Aspect of 2:1-Zn vitrimer composites slabs after welding, c) principle of the lap-shear test.

The reinforcing fabric pattern forms a corrugated surface alternating areas full of resin and areas where the glass fibers (GF) are almost bare. To alleviate this strong variability factor, we laid on top of the GF fabric plies a light cloth $\left(30 \mathrm{~g} / \mathrm{m}^{2}\right)$ of poly(ethylene terephthalate) (PET). The cloth ensures an essentially flat upper layer of matrix (see roughness analysis in ESI Figure S2) which allows contact to occur between the upper and the lower adherand's matrix despite the underlayer corrugation. Thus, the cloth improves test reproducibility and eliminates the need of very careful alignment of the lower and the upper adherand that would be essential to get the interstices in-between the weaving -that are full of matrix- to match. Furthermore, PET melt temperature $\left(260^{\circ} \mathrm{C}\right)$ was found to be a lot higher than the chosen adhesion temperature $\left(160^{\circ} \mathrm{C}\right)$. The vermicelli-like lines observed by microscopy on Figures $5 \mathrm{a}$ and $5 \mathrm{~b}$, characteristics of the cloth are preserved despite the adhesion process $\left(1 \mathrm{~h} 30\right.$ at $\left.160^{\circ} \mathrm{C}\right)$. Therefore, the cloth itself is not responsible for the adhesion. All the next presented experiments have been made using the cloth side.

The raw results of the joint tensile tests are listed in Table 1. F1, F2 and F3 are respectively the forces at break after the first, second and third welding procedure $\left(1 \mathrm{~h} 30\right.$ at $\left.160^{\circ} \mathrm{C}\right)$ of both epoxy vitrimer and control samples. Under a $500 \mathrm{~N}$ load (1.7 $\mathrm{MPa}$ ), none of the control 2:2 joints stuck neither at first nor second nor third welding. In the case of an adhesion under a higher load of $1320 \mathrm{~N}$ (4.4 MPa), control samples show measurable forces at first sticking. On average it corresponds to a third of what epoxy vitrimer samples display. Few control joints are slightly efficient at second sticking giving a mean force at break of $66 \mathrm{~N}$ and none of them stuck at the third welding attempt.

Table 1. Results of lap-shear tests of 2:1-Zn and 2:2 welded samples. All composite plates are postcured $3 \mathrm{~h}$ at $160^{\circ} \mathrm{C}$ before assembling. The welding was performed at $160^{\circ} \mathrm{C}$ during $1 \mathrm{~h} 30 . \mathrm{P}$ is the load applied on the $20 \mathrm{~mm} \times 15 \mathrm{~mm}$ overlap surface. F1, F2 and F3 are the values of force at break after first, second and third welding,respectively. The two last lines feature the mean results. [/: not measured] (Adherand thickness $=3 \mathrm{~mm}$ )

\begin{tabular}{|c|c|c|c|c|c|c|c|c|c|}
\hline \multicolumn{5}{|c|}{ Control 2:2 } & \multicolumn{5}{|c|}{ Vitrimer $2: 1-Z n$} \\
\hline $\begin{array}{c}\# \\
\text { sample }\end{array}$ & $\begin{array}{c}\mathrm{P} \\
{[\mathrm{N}]}\end{array}$ & $\begin{array}{l}\text { F1 } \\
\text { [N] }\end{array}$ & $\begin{array}{l}\text { F2 } \\
\text { [N] }\end{array}$ & $\begin{array}{l}\text { F3 } \\
\text { [N] }\end{array}$ & $\begin{array}{c}\# \\
\text { sample }\end{array}$ & $\begin{array}{c}\mathrm{P} \\
{[\mathrm{N}]}\end{array}$ & $\begin{array}{l}\mathrm{F} 1 \\
{[\mathrm{~N}]}\end{array}$ & $\begin{array}{l}\mathrm{F} 2 \\
{[\mathrm{~N}]}\end{array}$ & $\begin{array}{l}\text { F3 } \\
\text { [N] }\end{array}$ \\
\hline 1 & 500 & 0 & 0 & 0 & 11 & 500 & 440 & 516 & 1 \\
\hline 2 & 500 & 0 & 0 & 0 & 12 & 500 & 441 & 556 & 512 \\
\hline 3 & 500 & 0 & 0 & 0 & 13 & 500 & 363 & 478 & 492 \\
\hline 4 & 500 & 0 & 0 & 0 & 14 & 500 & 821 & 581 & 599 \\
\hline 5 & 500 & 0 & 0 & 0 & 15 & 500 & 248 & 391 & 392 \\
\hline 6 & 1320 & 261 & 47 & 0 & 16 & 1320 & 763 & 496 & 510 \\
\hline 7 & 1320 & 210 & 94 & 0 & 17 & 1320 & 861 & 353 & 470 \\
\hline 8 & 1320 & 235 & 0 & 0 & 18 & 1320 & 517 & 556 & 427 \\
\hline 9 & 1320 & 395 & 188 & 0 & 19 & 1320 & 620 & 532 & 493 \\
\hline \multirow[t]{2}{*}{10} & 1320 & 122 & 0 & 0 & 20 & 1320 & 667 & 605 & 570 \\
\hline & & & & & 21 & 1320 & 572 & 477 & 396 \\
\hline $1-5$ & 500 & 0 & 0 & 0 & $11-15$ & 500 & 463 & 504 & 499 \\
\hline $6-10$ & 1320 & 245 & 66 & 0 & $16-21$ & 1320 & 667 & 503 & 478 \\
\hline
\end{tabular}

Thus, for control samples, repeated welding is inefficient. A non negligible adhesion is observed at high load but only for the first welding attempt. Despite all postcuring precautions and the apparent stability of $\mathrm{Tg}$ (ESI, Table S2), remaining reactive functions may still be present in small amount at the surface. When applying a high pressure to a control sample joint, the area of contact increases, as pointed out in the introduction, up to enable the chemical bonding throughout the interface thereby resulting in a measurable debonding force. However, after several cycles remaining reactive functions get gradually exhausted and do not promote adhesion anymore. Such adhesion mode is highly sensitive to the thermal history and to the applied load, as indeed observed in control samples. 
In striking contrast, epoxy vitrimer samples exhibit an essentially constant force at break around 500N for every adhesion process, whatever the applied load, despite the inherently high dispersion of rupture tests. ${ }^{55}$ This result is a great indicator of the possibility of efficient multiple bonding for epoxy vitrimer composites solely and not for the epoxy control ones. It also shows that the applied load cannot be the most significant factor that explains epoxy vitrimer adhesion efficiency compared to its non vitrimer counterpart. Indeed, creep experiments showed that epoxy vitrimer matrix can flow and relax stress thanks to exchange reactions within the network whereas the control matrix essentially does not (Figure 3b). The contact area between adherands is no longer determined by the two-solids contact regime but by the epoxy vitrimer matrix flow, thus improving surface conformity and adhesion efficiency. Besides, an intimate contact between the epoxy vitrimer adherands further promotes the occurrence of exchange reactions and the formation of bonds at the interface of the two adherands.

In order to highlight the role of exchange reactions in the welding process, we also measured the force at break after first and second welding as a function of three different factors: A) the epoxy to anhydride ratio; B) the presence of the $\mathrm{Zn}$ catalyst and C) the value of the applied load. In order to evaluate the influence of each factor and their possible interactions $^{56}$ despite large experimental variability in the measurements, the experiments were organized according to a two-levels factorial design coupled with a Student-type analysis to evaluate the significance of the factors. ${ }^{57}$ The full data (Table S3) and details of methodology are gathered in the $\mathrm{ESI}$, the result is represented graphically in figure 5 . At the first welding event, factor B (stoichiometry) is the most influent, high welding strength being obtained solely with the 2:1 stoichiometry. The effect of zinc acetyl acetonate (factor A) only appears in its interaction with stoichiometry, which means that the effect of the catalyst depends on the stoichiometry. Indeed, the role of this reagent is double, on one hand it accelerates the curing reactions and then reduces the consequences of incomplete curing, on the other hand, it promotes exchanges by transesterification, whenever ester and hydroxide groups are present, as revealed by the large $A B$ interaction. Pressure also plays a significant role (factor $\mathrm{C}$ ) but its interaction with chemical factors is not significant. At the second welding, when incomplete curing effects are eliminated, the role of both chemical factors A and B clearly appears and their positive interaction $A B$ is confirmed but the influence of pressure is no longer found significant, which nicely confirms the results of 2:1-Zn versus $2: 2$ comparison.

The better adhesion efficiency of epoxy vitrimer composites can therefore be explained by both physical and chemical vitrimer properties of the 2:1-Zn matrix as depicted in Figure 1.

Macro and microscopic observations illustrated in Figure 6 confirmed the intimate bonding and the better adhesion efficiency of the vitrimer material compared to the control one. In fact, as featured in Figure $6 a$ and $6 \mathrm{c}$, the cloth layer, soaked with matrix, has cracked for many of the epoxy vitrimer samples as encircled and pointed by the arrows. Plus, cracks of the top adherand mirror the ones of the bottom one indicating that bonds were formed at the interface. These distinctive features have never been witnessed for the 2:2 reference samples (Figure $6 \mathrm{~b}$ and $6 \mathrm{~d}$ ) that present an essentially flat surface after rupture.

Effect (in Newton) of each factor and their interactions [NS: non significant]

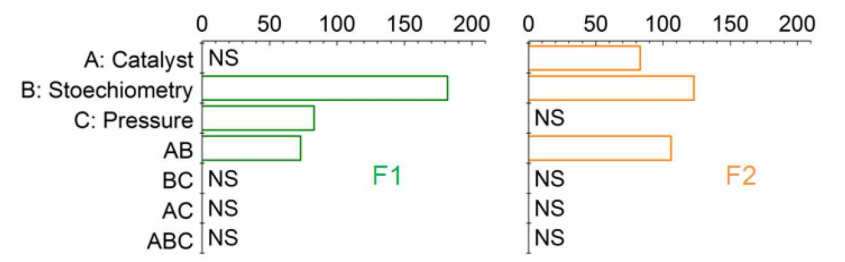

Figure 5. Histograms of the effects of factors and interactions (in newtons) for each response (F1: force at break at first welding; F2: at second welding) [NS: non significant].
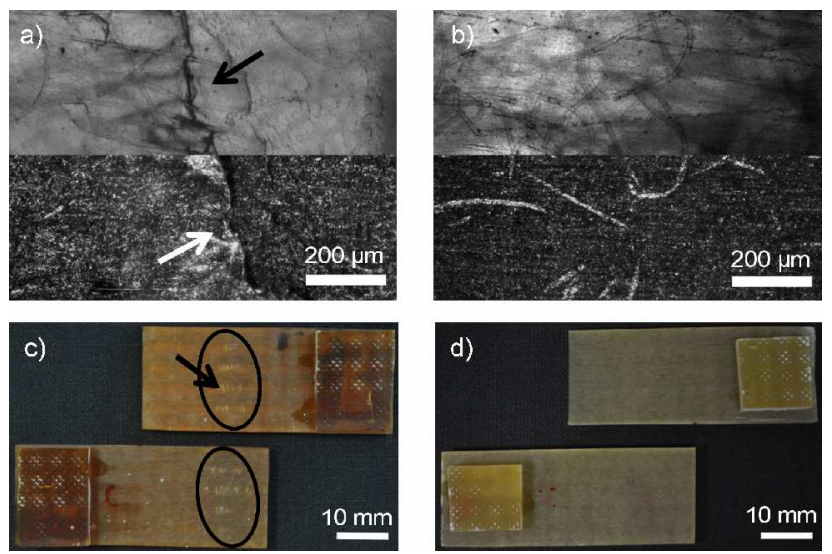

Figure 6. Microscopic observations by transmission (top) and reflection (bottom) of the surface of an epoxy vitrimer 2:1-Zn (a) and a reference 2:2 (b) lapjoint specimens after rupture $\left(1^{\text {st }}\right.$ sticking, $\left.160^{\circ} \mathrm{C}, 1 \mathrm{~h} 30,1.7 \mathrm{MPa}\right)$. Visual aspect of the same samples showing cracks on the epoxy vitrimer (c) and an essentially flat surface for the reference $(d)$.

\section{Conclusions}

In conclusion this work extends the epoxy vitrimer chemistry to a liquid formulation based on commercial composite matrix components and $\mathrm{Zn}(\mathrm{acac})_{2}$ the catalyst used in pionneer studies on vitrimers. We synthesized a crosslinked material that presents vitrimer properties and that is compliant with continuous fiber composite technology thanks to its low viscosity before cure, its acceptable gel time and its thermostability. We then prepared an epoxy vitrimer glass fiber composite by the resin transfer molding technique following a cure cycle very typical of a classical epoxy process. Yet there is room for optimization of the vitrimer properties. Monomer functionality can be adjusted (e.g. by blending with a tetrafunctional epoxy resin ${ }^{58}$ ) to increase both $\mathrm{Tg}$ and the plateau modulus. New recently patented vitrimer catalysts ${ }^{59}$ may be used as well to enhance properties, fasten the stress relaxation and increase thermal stability. We took advantage 
of the vitrimer properties to weld composites together without adhesive nor mechanical fasteners. We have then shown that best welding efficiency and multiple welding are only obtained when exchange reactions are likely to occur (in epoxy vitrimer) in comparison with control samples where such reactions are absent. We deliberately set a low welding temperature in order to study the underlying mechanisms of vitrimer composites adhesion. In these conditions, the ability to improve surface conformity by flowing and to form chemical bonds between the adherands were identified as distinctive features of vitrimers that both concur to achieve significant adhesion strengths. However by slightly changing the operating conditions $\left(180^{\circ} \mathrm{C}\right.$ during 25 minutes instead of $160^{\circ} \mathrm{C}$ during $1 \mathrm{~h} 30$ ), a force at break up to $2800 \mathrm{~N}$ was measured and the fracture surfaces were typical of a cohesive failure (shown in S.I.). Current structural adhesives typically show a force at break in the $2500-5000 \mathrm{~N}$ range in the same testing conditions, which shows that, beyond this model study, the mode of assembly introduced in this paper also allows to achieve high adhesion forces.

The presented results set this new method of assembly based on the vitrimer nature of the adherands as an alternative to classical joining techniques. For instance, the presented work could be of interest in industries such as naval or aerospace where big sized and/or hollow structures cannot be obtained by molding. Epoxy vitrimer welding reduces the adhesive layer, which is the weakest spot of an adhesive composite joint since it is unreinforced, to zero. The presented technique also offers an alternative to mechanical joining techniques that cause concentration of stresses and increased weight because of the fastener. Work is left to be done to get high bonding strengths competing with best structural adhesives, together with a low dispersion of results in order to enable the use of such technique. Plus, a more systematic study on the curing procedure could be beneficial for cost and time purposes. Vitrimers are not limited to epoxy. Research on new vitrimer chemistries is currently very active. Hard vitrimer materials based on polyactide, ${ }^{12}$ polyhydroxy-urethane, ${ }^{20}$ vinylogous urethane ${ }^{16}$ have been described. Some of these systems might be suitable to enter into the formulation of composites having similar welding capacity and where the findings of this study may also apply.

\section{Acknowledgements}

The authors gratefully acknowledge Ludwik Leibler for initiating this work and for many scientific discussions and experimental ideas which proved decisive for this work. Michel Cloître and Renaud Nicolaÿ are thanked for helpful discussions. ESPCI and CNRS are acknowledged for financial support. We thank the Institut de Soudure (formerly Pôle de Plasturgie de l'Est) for the preparation of composite plates and strong support.

\section{Notes and references}

1. D. Montarnal, M. Capelot, F. Tournilhac and L. Leibler, Science, 2011, 334, 965-968.

2. M. Capelot, M. M. Unterlass, F. Tournilhac and L. Leibler, ACS Macro Letters, 2012, 1, 789-792.

3. M. Capelot, D. Montarnal, F. Tournilhac and L. Leibler, J. Am. Chem. Soc., 2012, 134, 7664-7667.

4. X. Chen, M. A. Dam, K. Ono, A. Mal, H. Shen, S. R. Nutt, K. Sheran and F. Wudl, Science, 2002, 295, 1698-1702.

5. W. G. Skene and J.-M. P. Lehn, Proc. Natl. Acad. Sci. U.S.A., 2004, 101, 8270-8275.

6. Y. Higaki, H. Otsuka, A. Takahara, Macromolecules, 2006, 39, 2121-2125

7. R. F. M. Lange, M. van Gurp and E. W. Meijer, J. Polym. Sci. Part A: Polym. Chem., 1999, 37, 3657-3670

8. E. B. Stukalin, L.-H. Cai, N. A. Kumar, L. Leibler and M. Rubinstein, Macromolecules, 2013, 46, 7525-7541.

9 a) R. Nicolaÿ, J. Kamada, A. Van Wassen and K. Matyjaszewski, Macromolecules, 2010, 43, 4355-4361; b) Y. Amamoto, J. Kamada, H. Otsuka, A. Takahara and K. Matyjaszewski, Angew. Chem. Int. Ed., 2011, 50, 1660-1663.

10. J. B. Beck, J. M. Ineman and S. J. Rowan Macromolecules 2005, 38, 5060-5068.

11. H. Ying, Y. Zhang and J. Cheng, Nat. Commun., 2014, 5 Article number: 2918.

12. J. P. Brutman, P. A. Delgado and M. A. Hillmyer, ACS Macro Letters, 2014, 3, 607-610.

13. Z. Pei, Y. Yang, Q. Chen, E. M. Terentjev, Y. Wei and Y. Ji, Nat. Mater., 2014, 13, 36-41.

14. Y. Yang, Z. Pei, X. Zhang, L. Tao, Y. Wei and Y. Ji, Chem. Sci., 2014, 5, 3486-3492.

15. F. I. Altuna, V. Pettarin and R.J.J. Williams Green Chem., 2013,15, 3360-3366

16. W. Denissen, G. Rivero, R. Nicolaÿ, L. Leibler, J. M. Winne and F. E. Du Prez, Adv. Funct. Mater, 2015, 25, 2451-2457.

17. Y.-X. Lu, F. Tournilhac, L. Leibler and Z. Guan, J. Am. Chem. Soc, 2012, 134, 8424-8427.

18. M. M. Obadia, B. P. Mudraboyina, A. Serghei, D. Montarnal and E. Drockenmuller, J. Am. Chem. Soc, 2015, 137, 60786083.

19. P. Zheng and T. J. McCarthy, J. Am. Chem. Soc, 2012, 134, 2024-2027.

20 D. J. Fortman, J. P. Brutman, C. J. Cramer, M. A. Hillmyer and W. R. Dichtel, J. Amer. Chem. Soc, 2015, 137, 14019-14022.

21. W. Denissen, J. M. Winne and F. E. Du Prez, Chem. Sci., 2016, 7, 30-38.

22 T. F. Scott, A. D. Schneider, W. D. Cook and C. N. Bowman, Science, 2005, 308, 1615-1617.

23 C. J. Kloxin, T. F. Scott,B. J. Adzima and C. N. Bowman, Macromolecules 2010, 43, 2643-2653.

24. R. Fenoli, J. W. Wydra and C. N. Bowman, Macromolecules, 2014, 47, 907-915.

25 C. J. Kloxin and C. N. Bowman, Chem. Soc. Rev., 2013, 42, 7161-7173 
26. M. Pepels, I. Filot, B. Klumperman and H. Goossens, Polym Chem, 2013, 4, 4955-4965.

27. A. Rekondo, R. Martin, A. R. de Luzuriaga, G. Cabañero, H. J. Grande and I. Odriozola, Mater. Horiz., 2014, 1, 237-240.

28. L. Nicolais, M. Meo and E. Milella, Composite Materials: A Vision for the Future, Springer-Verlag London, 2011.

29. S. Costantino and U. Waldvogel Composite Processing: State of the Art and Future Trends in Epoxy Polymers: New Materials and Innovations J. P. Pascault and R. J. J. Williams Eds, Wiley-VCH Weinheim 2010.

30. C. Ageorges, L. Ye and M. Hou, Compos. Part A Appl. Sci. Manuf., 2001, 32, 839-857.

31 R.A. Grimm, Adv. Mater. Processes, 1995, 147, 27-30.

32 D. Stavrov and H. Bersee, Composites Part A, 2005, 36, 3954.

33. E. W. Godwin and F. L. Matthews, Composites, 1980, 11, 155-160.

34. M. J. Troughton, Handbook of Plastics Joining: A Practical Guide, William Andrew Inc. Norwich, NY, 2nd edn., 2008.

35. F. L. Matthews, P. F. Kilty and E. W. Godwin, Composites, 1982, 13, 29-37.

36. J. Wingfield, Int. J. Adhes. Adhes., 1993, 13, 151-156.

37. N. A. de Bruyne, Aircraft Engineering, 1944, 16, 115.

38. M. D. Banea and L. F. M. da Silva, Proc. Inst. Mech. Eng. L J. Mater. Des. Appl., 2009, 223, 1-18.

39. H. S. da Costa Mattos, A. H. Monteiro and R. Palazzetti, Mater. Des., 2012, 33, 242-247.

40. H. S. da Costa Mattos, E. M. Sampaio and A. H. Monteiro, Int. J. Adhes. Adhes. 2011, 31, 446-454.

41. J. R. Vinson, Polym. Eng. Sci., 1989, 29, 1332-1339.

42. M. A. M. Rahmathullah and G. R. Palmese, J. Appl. Polym. Sci., 2009, 113, 2191-2201.

43. S. A. Hayes, F. R. Jones, K. Marshiya and W. Zhang, Compos. Part A Appl. Sci. Manuf., 2007, 38, 1116-1120.

44 X. Luo, R. Ou, D. E. Eberly, A. Singhal, W. Viratyaporn, P. T. Mather ACS Appl. Mater. Interfaces, 2009, 1, 612-620

45. C. Creton and L. Leibler, J. Polym. Sci., Part B: Polym. Phys., 1996, 34, 545-554.

46. J. Greenwood and J. Williamson, Proc. R. Soc. London, Ser. A, 1966, 295, 300-319.

47. ISO527-1:2012 Plastics - Determination of tensile properties.

48. Araldite LY564/Aradur 917CH/Accelerator 960-1 hot curing epoxy system data sheet, Huntsman 2004.

49. R. Wegler, Härtung von Epoxydharzen mit cyclischen Dicarbonsaüreanhydriden in Houben-Weyl Methoden der Organischen Chemie; Georg Thieme: Stuttgart, 1963; Vol.14, p 511

50. G.C. Stevens J. of Appl. Polym. Sci. 1981, 26, 4259-4278.

51 L. Matějka, S. Pokomý and K. Dušek Polymer Bull., 1982, 7, 123-128.

52 G. Rudolph, M. C. Henry, Inorg. Chem. 1964, 3, 1317-1318.

53. L. F. M. da Silva, P. C. das Neves, R. D. Adams, A. Wang and J. K. Spelt, Int. J. Adhes. Adhes., 2009, 29, 331-341.

54. ISO 4587:2003 Adhesives -- Determination of tensile lapshear strength of rigid-to-rigid bonded assemblies.
55. A. V. Pocius, Adhesion and Adhesives Technology 3rd ed. Carl Hanser Verlag, Munich 2012, p. 81.

56 J.N. Miller and J.C. Miller Statistics and Chemometrics for Analytical Chemistry, Prentice Hall, Harlow, 2010, p.193

57 D.L. Massart, B.G.M. Vandeginste, L.M.C. Buydens, S.D. Jong, P.J. Lewi and J. Smeyers-Verbeke Handbook of Chemometrics and Qualimetrics: Part A, Elsevier, Amsterdam, 1997, p.659

58 F. Sordo, S.J. Mougnier, N. Loureiro, F. Tournilhac and V. Michaud, Macromolecules, 2015, 48, 4394.

59 C. Duquenne, S.-J. Mougnier, F. Tournilhac and L. Leibler WO2015162387 (A2) - 2015-10-29. 